\title{
Self-lubrication of tribologically-induced oxidation during dry reciprocating sliding of aged $\mathrm{Ti}-\mathrm{Ni5} 1.5$ at\% alloy
}

\author{
Rui YANG ${ }^{1,2}$, Wei MA ${ }^{1,2}$, Chunjian DUAN ${ }^{1,2}$, Song LI $^{1,2}$, Tingmei WANG ${ }^{1,2}$, Qihua WANG ${ }^{1,2,}$ \\ ${ }^{1}$ State Key Laboratory of Solid Lubrication, Lanzhou Institute of Chemical Physics, Chinese Academy of Sciences, Lanzhou 730000, China \\ ${ }^{2}$ Center of Materials Science and Optoelectronics Engineering, University of Chinese Academy of Sciences, Beijing 100049, China
}

Received: 29 October 2019 / Revised: 14 February 2020 / Accepted: 07 April 2020

(C) The author(s) 2020 .

\begin{abstract}
The tribological behaviors of Ti-Ni51.5 at \% alloy strengthened by finely dispersed $\mathrm{Ni}_{4} \mathrm{Ti}_{3}$ particles in reciprocating sliding against $\mathrm{GCr} 15, \mathrm{Al}_{2} \mathrm{O}_{3}$, and $\mathrm{ZrO}_{2}$ at room temperature were studied. Interestingly, the coefficient of friction (COF) suffered a sheer drop (from 0.9 to 0.2 ) when the aged alloy slid against GCr15 at a frequency of $20 \mathrm{~Hz}$ under a $20 \mathrm{~N}$ load without lubrication. However, severe-mild wear transition disappeared when a solutionized alloy was used. Moreover, the COF stabilized at a relatively high level when $\mathrm{Al}_{2} \mathrm{O}_{3}$ and $\mathrm{ZrO}_{2}$ were used as counterparts, although their wear mechanisms showed signs of oxidation. Scanning electron microscopy (SEM) and X-ray element mappings of the wear scars of the counterparts clearly indicate that the formation of well-distributed tribo-layer and material transfer between the ball and disk are pivotal to the severe-to-mild wear transition in the aged Ti-Ni51.5 at\% alloy/GCr15 friction pair. The higher microhardness and superelasticity of the aged alloy significantly accelerate the material transfer from GCr15 to the disk, forming a glazed protective tribo-layer containing Fe-rich oxides.
\end{abstract}

Keywords: self-lubrication; tribologically-induced oxidation; Ti-Ni51.5 at\% alloy; dry reciprocating sliding; counterparts

\section{Introduction}

TiNi-based shape-memory alloys (SMAs) have been widely applied in several industries owing to their excellent shape memory behaviors and superelasticity (SE) [1]. Their potential SE adds to the combination of high coefficient of friction (COF) and an impressive wear resistance, which incites researchers to investigate them as wear-resistant materials [2-5]. The existing studies on the tribological applications of TiNi SMAs primarily illustrate the influence from the microstructure and experimental conditions on its tribological behaviors, e.g., phase states [6], grain size [2], temperature [7], and loading [8]. The tribological features of SMAs significantly depend on stress induced martensitic (SIM) transformation and reversible transformation [2, 9-11], and no efforts have been spared to study the oxidation of TiNi SMAs induced by dry sliding.

Tribologically modified microstructures, often referred to as "tribo-layers", are critical to the tribological performance of the materials [12-14]. The surface modification of metals by tribological loading is typically explained as a mechanically-driven process due to the friction energy being mostly absorbed by sliding-induced plastic deformations [15]. However, the potentially complex chemical reactions occurring under the tribological contact are highly crucial to the tribological behaviors as the tribo-layers affect the contact mechanics profoundly [13, 16]. Tribo-layers, particularly the topmost layer, directly in contact with the environment and their counterpart, primarily determine the friction and generate wear $[13,17,18]$. Controlling the chemical and mechanical properties

* Corresponding author: Qihua WANG, E-mail: wangqh@licp.cas.cn 
of tribo-layers can dramatically improve the tribological performance, as recently discovered with the severemild wear transition of the metal materials [16, 19]. Uncertain local temperatures, mechanically-driven chemical reactions, and the contact with another body may be factors governing this phenomenon, which was observed in several recent studies involving $\mathrm{Cu}$ alloys with stable gradient nanostructures [20], $\mathrm{Pt}-\mathrm{Au}$ with stable nanocrystalline [21], Ti alloys [16, 22], and steels with martensite and pearlite structures [18]. Zhang et al. [16] investigated the sliding velocityinduced transition from severe wear to mild wear as a result of the formation of tribo-oxide layers during the Ti-6.5Al-3.5Mo-1.5Zr-0.3Si sliding against GCr15. Furthermore, a fundamental research on wear transition regimes of Ti against steel was conducted [22]. These detailed researches indicate that the oxide particles play a critical role in the severe-mild wear transition during sliding. However, this phenomenon also closely depends on several factors, such as loading, temperature, and velocity. A study exploring the improvement of the wear performance of Ti-6Al-4V alloy during sliding against AISI 52100 steel showed that $\mathrm{Fe}_{2} \mathrm{O}_{3}$ nanoparticles have a noticeable advantage over $\mathrm{TiO}_{2}$ in decreasing the COF of $\mathrm{Ti}$ alloy by artificially supplying nanoscale oxides of $\mathrm{TiO}_{2}, \mathrm{Fe}_{2} \mathrm{O}_{3}$, or their mixtures onto sliding tracks [23].

In contrast to the increasingly valuable researches investigating the oxidization of $\mathrm{Ti}$ alloy during dry sliding friction, the chemically different layer induced during tribologically sliding in TiNi alloys has not been significantly studied. Furthermore, the counterpart is a significant factor deeply influencing the friction behavior, which is still not well understood at present. In this study, we report the benefits of tribo-layers showing distinct lubrication in the aged Ni-rich Ti-Ni51.5 at\% alloy when sliding it against GCr15. The self-organizing process leads to the formation of alternating oxidization and achieves very low friction, but this phenomenon is not present when slid against $\mathrm{Al}_{2} \mathrm{O}_{3}$ or $\mathrm{ZrO}_{2}$. However, the tribo-layers introduced when the solutionized TiNi alloy slid against GCr15 did not act as a lubricant even in the same experimental conditions. We conducted a series of experiments, such as scanning electron microscopy (SEM), energy dispersive X-ray spectroscopy (EDX), and X-ray photoelectron spectroscopy (XPS), to explore the relationships between tribo-oxides and friction behaviors of the TiNi alloys.

\section{Materials and methods}

The commercial Ni-rich Ti-Ni51.5 at\% alloy used was cut into disks $(\varphi 24 \mathrm{~mm} \times 2.7 \mathrm{~mm})$ and bone-shaped sheets and subsequently placed into well-closed quartz tubes filled with low-pressure argon to avoid oxidization. All disks and sheets were solutionized at $1,000{ }^{\circ} \mathrm{C}$ for $1 \mathrm{~h}$, and a part of them was then aged at $500{ }^{\circ} \mathrm{C}$ for $1 \mathrm{~h}$. The plates were electro-polished to receive a fresh surface after being grinded by $\mathrm{SiC}$. The microhardness of Ti-Ni51.5 at $\%$ alloy was acquired by applying a load of $300 \mathrm{~g}$. The tensile tests were conducted at a strain rate of $6.67 \times 10^{-4} \mathrm{~s}^{-1}$ on a traditional tensile testing instrument. The samples were first stretched by a $6 \%$ strain and subsequently unloaded below $7 \mathrm{MPa}$ to obtain their superelasticity. The Netzsch-STA449F3 differential scanning calorimeter (DSC) was used to characterize the austenite start (As) and martensite start (Ms) temperature. Reciprocating sliding wear tests of TiNi pieces were performed using an Optimol SRV IV tester in a ball-on-disk contact configuration (Fig. 1) at $20^{\circ} \mathrm{C}$ in an environment with a relative humidity of approximately $45 \%$. The load, stroke, and frequency were kept constant at $20 \mathrm{~N}, 1 \mathrm{~mm}$, and $20 \mathrm{~Hz}$, respectively. The friction and wear tests were carried out using GCr15 steel, $\mathrm{Al}_{2} \mathrm{O}_{3}$, and $\mathrm{ZrO}_{2}$ ball with a diameter of $10 \mathrm{~mm}$ acting as the tribo-pair materials under dry condition. The oxidization was effectively suppressed by adding PAO10 lubrication (poly alpha olefin) on the surface during the wear tests of the TiNi alloys sliding against GCr15.

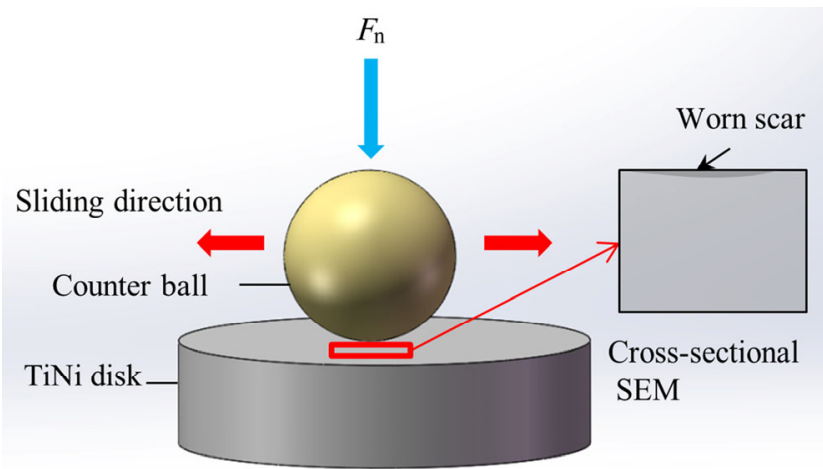

Fig. 1 Schematic of the ball-on-disk contact. 
The microstructures of the samples before wear were analyzed by an optical microscope (OM) conducted on a ZEISS Imager, X-ray diffraction (XRD) at ambient temperature on a D8Discover25 with $\mathrm{Cu}$ $\mathrm{K} \alpha$ radiation, and transmission electron microscope (TEM) on Tecnai G2 TF20 at $200 \mathrm{kV}$. The characteristics of the worn surfaces of the TiNi alloy and counterparts were investigated by SEM on Thermoscientific-Apreos and EDX. To determine the chemical states of the elements in the surface layer of the worn scar, we conducted XPS, which provides information about the valence band structure, and a cross-sectional EDX observation was applied parallel to the sliding direction to gain more information.

\section{Results and discussion}

\subsection{Microstructural and calorimetric features before friction}

The microhardness increased from 2,807 to 3,651 MPa when Ti-Ni51.5 at \% experienced aging at $500{ }^{\circ} \mathrm{C}$ for $1 \mathrm{~h}$ after the treatment of the solution. This increase corresponds to the strength of the nanosized particles. The undeformed microstructures of Ti-Ni51.5 at $\%$ after the heat treatment are shown in Fig. 2. Nearequiaxed grains of approximately $50 \mu \mathrm{m}$ are observed in the aged and solutionized states, as displayed in Fig. 2(a). Nano-sized precipitates were embedded in the matrix after being aged for $1 \mathrm{~h}$, as shown in Fig. 2(b), whereas several dislocations were present in the B2 phase, as shown in Fig. 2(c). The XRD patterns in Fig. 2(d) indicate that the precipitates are $\mathrm{Ni}_{4} \mathrm{Ti}_{3}$, which has been widely confirmed in some existing studies [24, 25]. The volume fraction and size of the precipitates profoundly influence the martensitic transformation temperature, which is a fundamental parameter in the determination of the properties of TiNi alloys. The results of DSC show As $=29.4{ }^{\circ} \mathrm{C}$ and $\mathrm{Ms}=-31.1^{\circ} \mathrm{C}$ in the aged alloy, and Ms is below $-120^{\circ} \mathrm{C}$ in the solutionized alloy, which illustrates that the matrix of both alloys will be in the B2 state before the wear test at room temperature. The elastic modulus substantially affects the contact stress according to the Hertz theory, while the superelasticity of the TiNi alloy significantly influences its wear behavior [6-8]. Tensile tests were conducted to evaluate the difference in elastic modulus and superelasticity between both alloys. Figure 2(f) presents the tensile curves of the alloys in different heat treatment states. Moreover, the static Young's modulus is 20.47 and $28.98 \mathrm{GPa}$ for the solutionized and aged alloys, respectively. Additionally, it shows that the aged alloy exhibits better superelasticity.
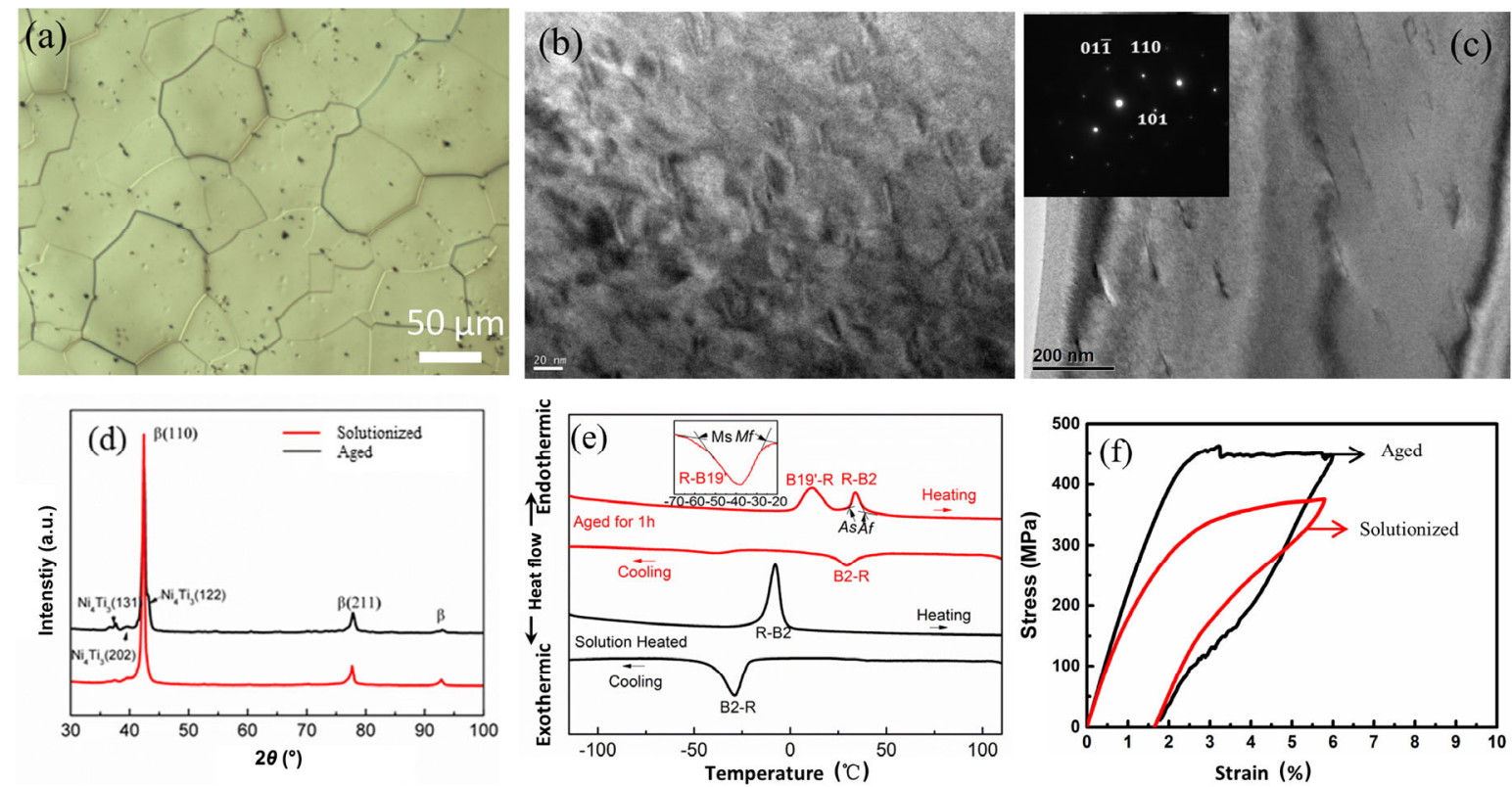

Fig. 2 Features of Ti-Ni51.5 at\%: (a) under OM; (b, c) bright field micrographs of alloys in aged and solutionized states, respectively. (d) XRD patterns; (e) DSC curves; and (f) tensile curves. 


\subsection{Frictional and wear results}

\subsubsection{Low-friction behavior}

Figures 3(a) and 3(b) show the COF curves as a function of time for the aged and solutionized samples, respectively. The COF for both alloys increases to a high value rapidly in a very short time during the initial transient running time and stick-slip behavior, which is similar to the results of previous research on the tribology of TiNi during dry sliding [7]. The COF stabilizes at a high value; however, it decreases abruptly in the case of the aged TiNi-GCr15 friction pair, and a stable low-friction period starts in the friction process. A similar phenomenon was identified in the study of dry sliding wear tests associated with the nano-lamellar microstructures [19] and was ascribed to the formation of a self-lubricating layer. However, this change was absent in the friction test of the solutionized alloy in Fig. 3(b). PAO10 was applied to alleviate the oxidization during the dry sliding of the aged TiNi/GCr15 friction pair. During the initial stage, the friction is low, smooth, and noise-free. Wear starts to occur in the second stage, where the COF value increases due to the partial breakage of the lubricant film caused by oil consumption [3]. The COF tends to remain at a high value with moderately wide fluctuations and maintains this level until the end of the test. The results seem to be reasonable. Figure 3(c) displays XRD patterns of the Ti-Ni51.5 at \% alloy subjected to sliding wear. $\mathrm{TiO}_{2}$ appears in all the wear tracks subjected to dry sliding against $\mathrm{Al}_{2} \mathrm{O}_{3}, \mathrm{ZrO}_{2}$, or GCr15. Furthermore, $\mathrm{B}^{\prime} 9^{\prime}$ is introduced during the sliding owing to the contact stress. However, peaks of $\mathrm{Fe}_{2} \mathrm{O}_{3}$ and $\mathrm{FeO}$ appear when GCr15 was used without the lubrication of PAO10, which, clearly indicates that the oxides of GCr15 retained on the worn surfaces are largely responsible for the severe-mild transition. For TiNi shape memory alloys, a related study showed that the COF of martensite (about 0.6) is slightly lower than austenite (0.8) due to its lower strength [6]. However, SIMs were left at the wear scars of both the aged and solutionized alloys (Fig. 3(c)), indicating that the alloys have undergone SIM transformations during the friction process. In other words, the contact is between GCr15 and martensite in the steady state friction for both the solutionized and aged alloy. However, the solutionized alloy does not present COF abruption. Therefore, the change in the COF here may not be caused by the difference between austenite and martensite. Figure 2(f) shows that there is a slight difference in the static Young's moduli for the solutionized $\left(E_{\mathrm{s}}=20.47 \mathrm{GPa}\right)$ and aged $\left(E_{\mathrm{a}}=28.98 \mathrm{GPa}\right)$ alloy primarily caused by the superelasticity. The mass loss of the TiNi disks, as shown in Fig. 3(d) clearly
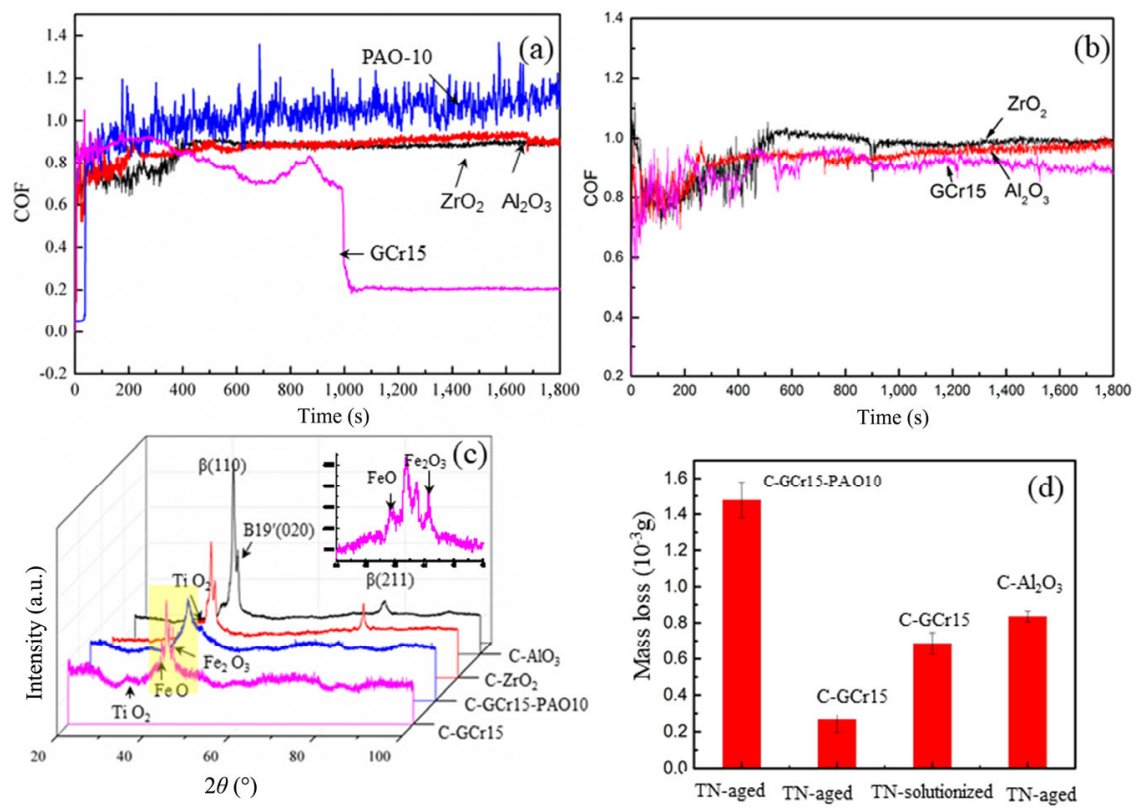

Fig. 3 COF during sliding against different counterparts for (a) aged and (b) solutionized Ti-Ni51.5 at\%. (c) XRD patterns of the wear tracks for aged ones and (d) the mass loss of the disks. 
suggests solutionized alloy sustained heavy wear, which is consistent with the change of COF. The mass loss is a result of fractures at the contacting asperities and is very high when PAO10 was applied, while the adhesive and abrasive wear prevailed. However, the wear loss is low when oxidative wear occurs. Notably, the aged TiNi alloy subjected to dry sliding against GCr15 shows the lowest mass loss as the wear is caused by the slight spalling of the tribo-layer.

\subsubsection{SEM, EDX, and XPS analysis of the worn surfaces of TiNi alloy}

The worn surfaces of the aged and solutionized Ti-Ni51.5 at $\%$ alloys were carefully identified to investigate the mechanisms behind the sever-mild wear transition, as shown in Fig. 4 . In the case of the aged Ti-Ni51.5 at\%-GCr15 during dry sliding, the worn surfaces are covered with a well-distributed tribo-layer (Fig. 4(a)), which is quite distinct from the other fictional pairs. Surfaces are composed of compacted particles with a uniform size, which may explain the abrupt decrease of COF. However, the wear tracks in Fig. 4(b) were significantly changed when PAO10 was used for lubrication. They exhibited wide grooves and striations parallel to the sliding direction characteristic of the plastic deformation of the alloy $[3,10]$ caused by the reciprocating motion of the counterparts. Lumps frequently appear on the wear surface of the alloys, albeit with different characteristics. Various reasons (i.e., plowed accumulations, adherence of plastically deformed materials, and compaction of the wear debris and oxidation) caused the micromorphology of the worn surfaces, according to wear tests. In the cases for the sliding against $\mathrm{Al}_{2} \mathrm{O}_{3}$ and $\mathrm{ZrO}_{2}$ counterparts, numerous islands in the wear tracks were randomly distributed on the worn surfaces (Figs. 4(c)-4(d) with the inset of magnified images of wear debris). However, for the solutionized alloy sliding against GCr15, apart from some delaminated tribo-layer, the worn surfaces were characterized by the presence of grooves (Figs. 4(e) and 4(f)).

Figures 5-7 exhibit the element-mappings of the wear tracks of TiNi alloy. For the surface of the aged TiNi alloy subjected to dry sliding against GCr15 (Fig. 5), a protective layer composed of the oxidation of $\mathrm{Fe}$ and $\mathrm{Ti}$ was formed during the friction process. The $\mathrm{O}$ concentration of the wear scars is extremely
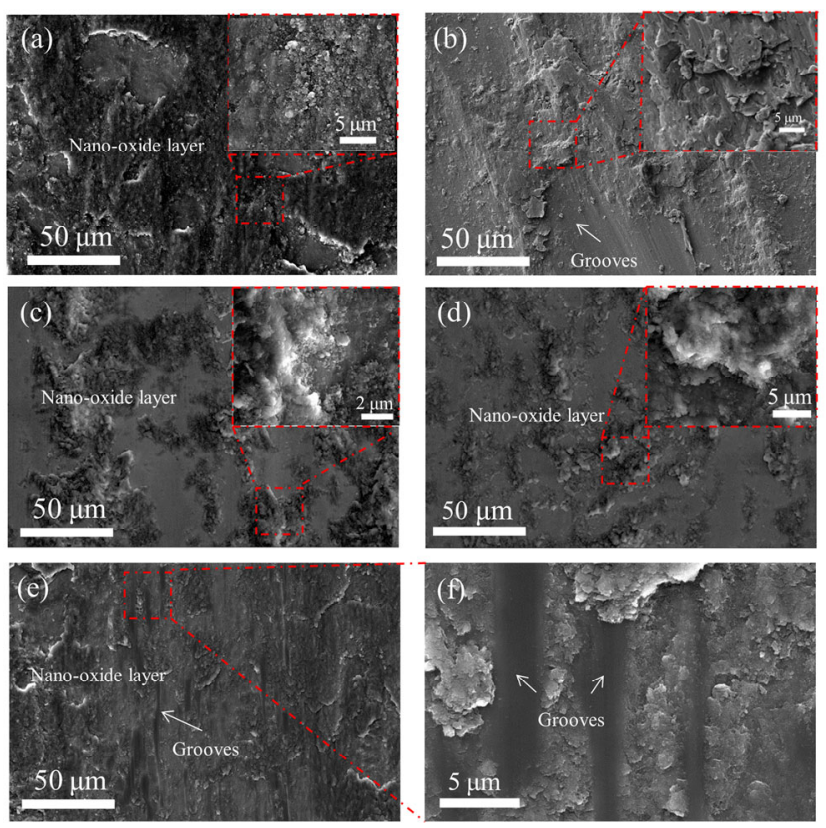

Fig. 4 SEM micrographs of the wear tracks under different wear conditions for aged TiNi: sliding against GCr15 (a) under dry friction and (b) being lubricated with PAO10; (c, d) sliding against $\mathrm{Al}_{2} \mathrm{O}_{3}$ and $\mathrm{ZrO}_{2}$, respectively. (e, f) SEM micrographs of the wear tracks for solutionized TiNi against GCr15.
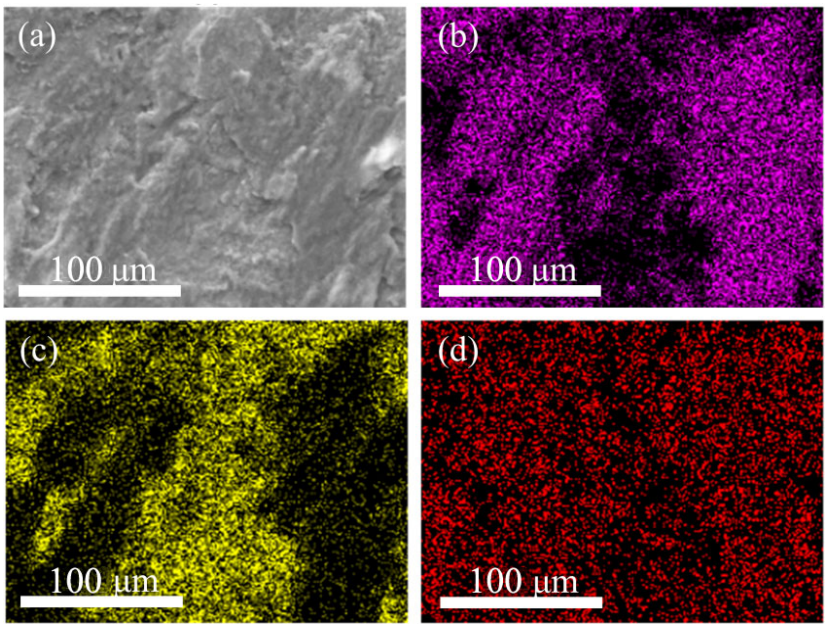

Fig. 5 (a) SEM image and EDS analysis of the tribo-layer formed when sliding against GCr15 during dry sliding on aged TiNi surface: $(b-d)$ chemical mapping of $\mathrm{Fe}, \mathrm{Ti}$, and $\mathrm{O}$, respectively.

high and distributed throughout the surface. The wear surface on the disk displays a high level of $\mathrm{Fe}$, indicating the occurrence of a material transfer from the ball. The Ti is distributed evenly on the worn surface, clearly illustrating that the tribo-layer is a mechanical mixture of the oxidization of $\mathrm{Ti}$ and $\mathrm{Fe}$. For the solutionized alloy, the EDX (Fig. 6) shows similar results. However, for the surface lubricated 

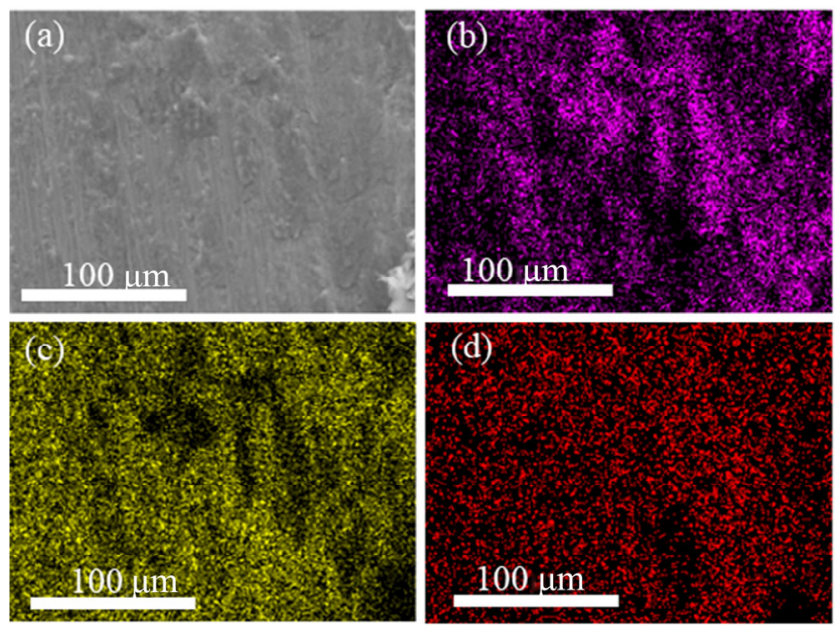

Fig. 6 (a) SEM image and EDS analysis of the tribo-layer formed when sliding against GCr15 during dry sliding on solutionized TiNi surface: (b-d) chemical mapping of $\mathrm{Fe}, \mathrm{Ti}$, and $\mathrm{O}$, respectively.

with PAO10 (Fig. 7), the Fe and O nearly vanish completely compared with that in Fig. 5. This confirms that PAO10 effectively suppresses the generation of the oxidation of $\mathrm{Ti}$ and $\mathrm{Fe}$ during dry sliding. The $\mathrm{O}$ concentration of the wear scars is extremely low and is attributed to severe plastic deformation.

Wear tests with $\mathrm{Al}_{2} \mathrm{O}_{3}$ and $\mathrm{ZrO}_{2}$ were conducted to investigate the influence of the counterpart on the tribology behavior of the TiNi alloy. Figure $8(\mathrm{~b})$ shows the areas with high O-concentrations in the EDX-element mapping of $\mathrm{O}$. $\mathrm{Ti}$ and $\mathrm{Ni}$ distribute uniformly and cover the entire wear surface. Neither the quantity of $\mathrm{Ti}$ nor that of $\mathrm{Ni}$ was increased in the areas with high $\mathrm{O}$-concentrations, thereby complicating
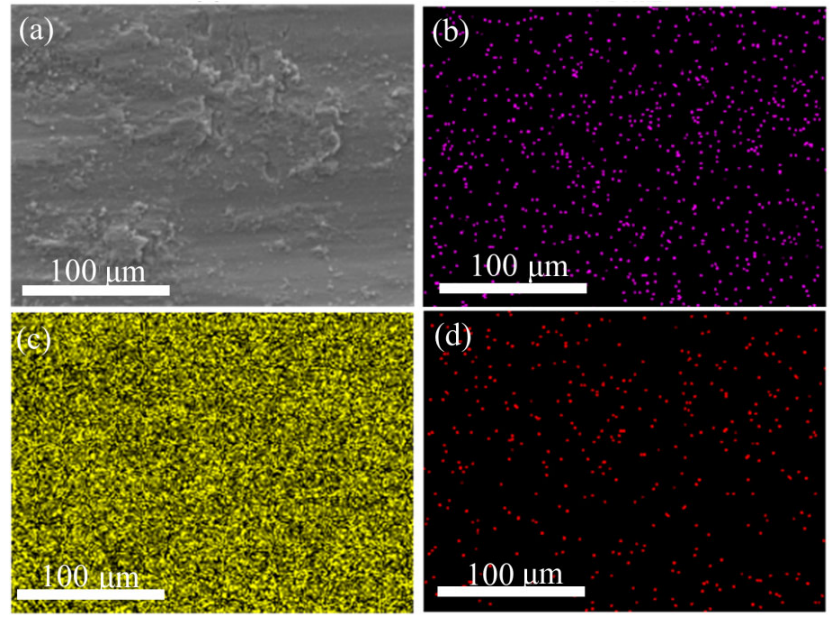

Fig. 7 (a) SEM image and EDS analysis of the surface when sliding against GCr15 with PAO10 lubrication: (b-d) chemical mapping of $\mathrm{Fe}, \mathrm{Ti}$, and $\mathrm{O}$, respectively.
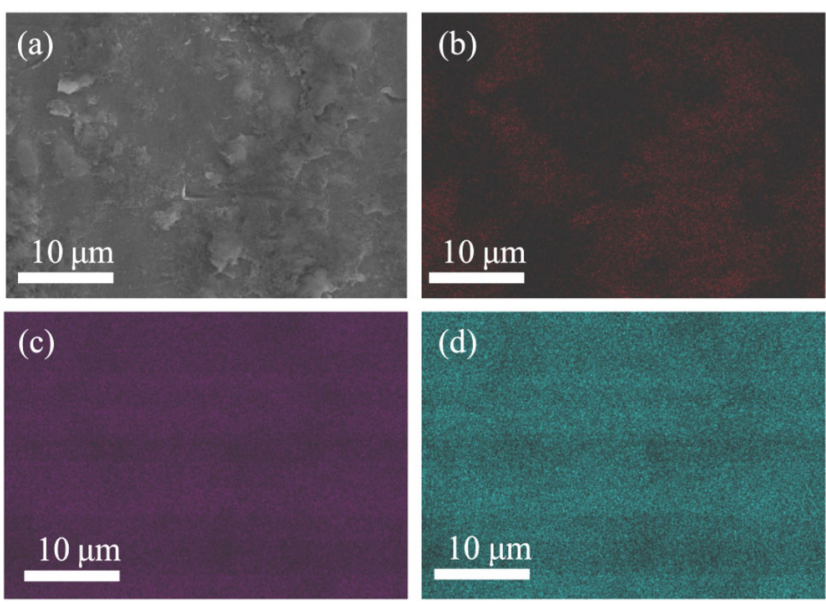

Fig. 8 (a) SEM image and EDS analysis of the surface when sliding against $\mathrm{Al}_{2} \mathrm{O}_{3}$ : (b-d) chemical mapping of $\mathrm{O}, \mathrm{Ni}$, and $\mathrm{Ti}$, respectively.

the identification of different types of oxides particles. Therefore, XPS was conducted to distinguish them clearly.

The oxide particles are considered to impact the tribological behaviors of metals during sliding [18, 23, 26]. Further, Fig. 9 demonstrates the XPS of the wear scars of TiNi alloy. Figures 9(b) and 9(e) represent the Ti $2 p$ spectra when the alloy is sliding against GCr15 and $\mathrm{Al}_{2} \mathrm{O}_{3}$, respectively, without lubrication. The different deconvolution peaks illustrate various oxide species (different valence states of $\mathrm{Ti}$ ). In the case of the TiNi tribo-layer, the spectrum fit is executed by assuming that four components are present: two oxide states $\left(\mathrm{Ti}^{3+}\right.$ and $\left.\mathrm{Ti}^{4+}\right)$ for the $\mathrm{Ti} 2 \mathrm{p}_{1 / 2}$ photoelectron peak and the same oxide states for the Ti $2 \mathrm{p}_{3 / 2}$ peak, similar to the study on the TiNi alloy oxidization [4]. Additionally, the binding energies of all the peaks concur with the values available in the existing studies [27]. The catching of $\mathrm{Ti}^{3+}\left(\mathrm{Ti}_{2} \mathrm{O}_{3}\right)$ indicates the formation of sub-oxides in the multiple layers. The deconvolution of the peaks of $\mathrm{Fe} 2 \mathrm{p}_{3 / 2}$ (Fig. 9(a)) reveals four peaks at 708.5, 709.4, 710.3, and $713.0 \mathrm{eV}$, which correspond to $\mathrm{Fe}^{2+}\left(\mathrm{Fe}_{3} \mathrm{O}_{4}\right), \mathrm{Fe}^{2+}\left(\mathrm{FeO}-\right.$ like), $\mathrm{Fe}^{3+}\left(\mathrm{Fe}_{2} \mathrm{O}_{3}\right)$, and $\mathrm{Fe}^{2+}$ satellite, respectively [28]. This implies the successful transfer of Fe onto the surfaces of the TiNi alloys and formation of iron oxides in the film. The peaks of $\mathrm{O} 1 \mathrm{~s}$ in Fig. 9(c) comprises three peaks at $529.2 \mathrm{eV}$ (O-Ti) [29], $530.4 \mathrm{eV}(\mathrm{O}-\mathrm{Fe})$ [28], and $531.5 \mathrm{eV}\left(\mathrm{OH}^{-}\right)$ [4]. In comparison to the spectra (Fig. 9(f)) for the surface sliding against $\mathrm{Al}_{2} \mathrm{O}_{3}$, the $\mathrm{O}-\mathrm{Fe}$ peaks are evident in the spectra for the scars. The detection of 

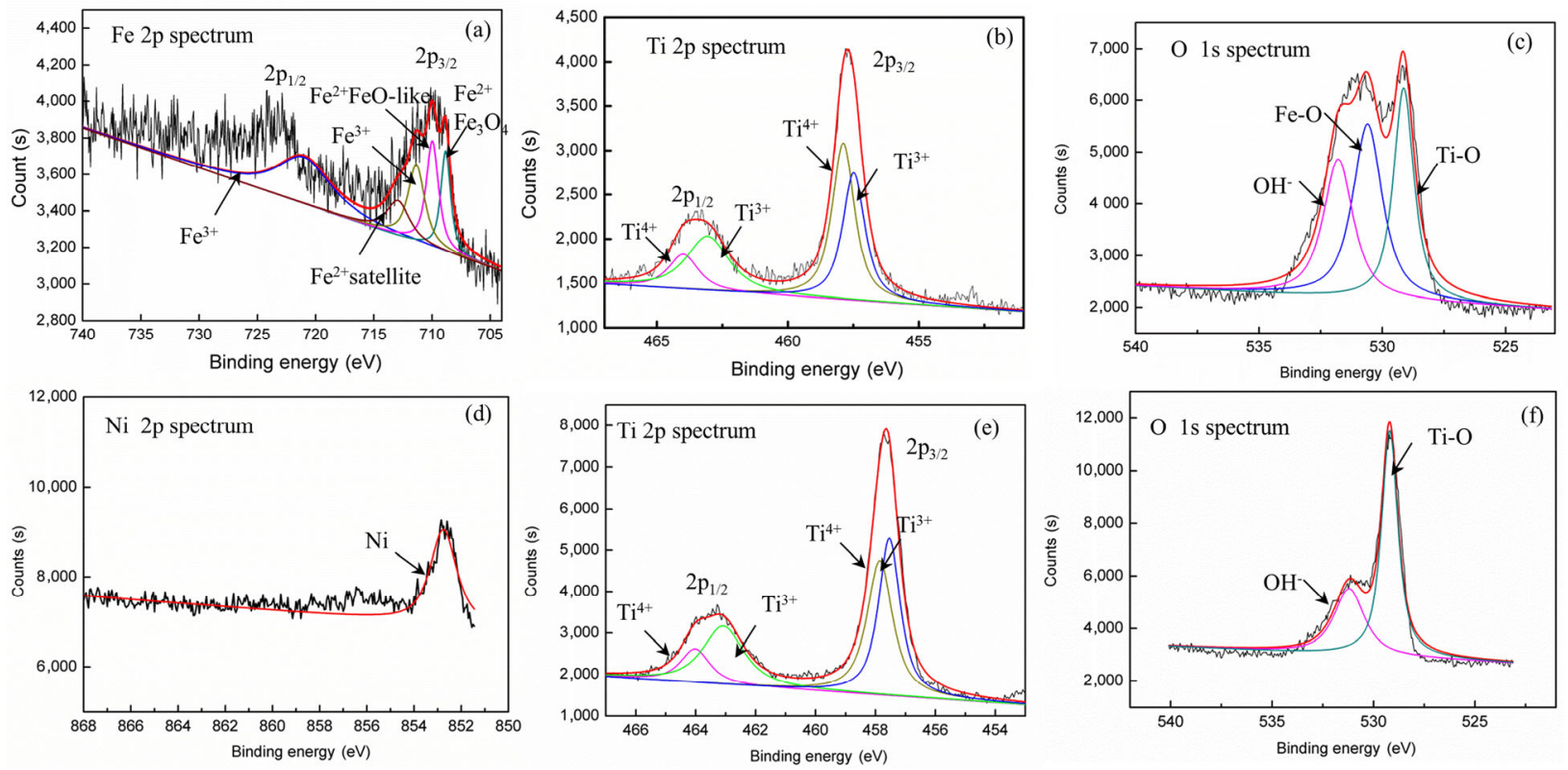

Fig. 9 XPS spectra of the wear tracks: (a-c) Fe 2p, Ti 2p, and O 1s spectra under the counterpart of GCr 15; (d-f) Ni 2p, Ti 2p, and O 1s spectra under the counterpart of $\mathrm{Al}_{2} \mathrm{O}_{3}$.

$\mathrm{OH}^{-}$in the surface layers is mainly caused by air. The Ni $2 p$ spectrum of the wear scars (Fig. 9(d)) shows the presence of only some unoxidized $\mathrm{Ni} 2 \mathrm{p}_{3 / 2}$ at $852.8 \mathrm{eV}$ [4]. The analysis of the XPS spectra suggests that the high-friction wear changing into low-friction wear is majorly caused by the oxidation of $\mathrm{Fe}$ and $\mathrm{O}$ on the worn surfaces. The surface layer consists of particles such as $\mathrm{TiO}, \mathrm{Fe}_{2} \mathrm{O}_{3}$, and $\mathrm{Fe}_{3} \mathrm{O}_{4}$. Typically, the $\mathrm{Fe}_{2} \mathrm{O}_{3}$ nanoparticles supplied to the wear scars [26] and the oxidization of the alloy are beneficial for the severe-mild wear.

The deformation and fracture of the initially transferred fragments during continuous sliding contact led to the formation of a "mechanically mixed material" on the surfaces of the matrix subjected to wear $[18,19,22]$. The mixed material layer formed under unlubricated conditions displays considerably higher hardness than the soft disk material due to the localized and thermal effects induced during the friction process [30]. The disks were sectioned along the sliding direction for further investigation to characterize the diverse tribo-layers. Figure 10 exhibits the cross-sectional SEM images with an EDS line analysis of the aged TiNi alloy after sliding under different experimental conditions. Cracks can be observed distinctly in the subsurface images of the samples when the alloy was slid against $\mathrm{GCr} 15, \mathrm{Al}_{2} \mathrm{O}_{3}$, and $\mathrm{ZrO}_{2}$ under dry friction. The strong adhesion between the ball and $\mathrm{TiNi}$ surfaces facilitates the evolution of these cracks [3]. Iron was clearly transferred to the tribo-layer, and the amount of oxygen significantly increased during the dry sliding against GCr15 in Fig. 10(a). Alternatively, this phenomenon disappears in Figs. 10(b)-10(d). The high aluminum content present in Figs. 10(c) and 10(d) is from the procedure applied to acquire the SEM images.
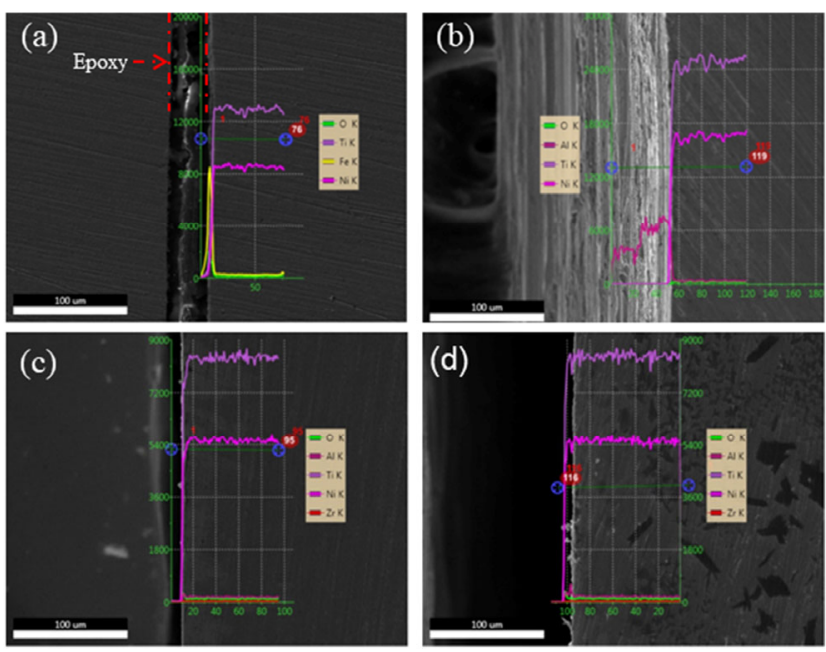

Fig. 10 Cross-section morphology of the worn surfaces and subsurfaces of TiNi alloy with a line map of EDX: sliding against GCr15 (a) under dry friction, (b) lubricated with PAO10, (c) $\mathrm{Al}_{2} \mathrm{O}_{3}$, and (d) $\mathrm{ZrO}_{2}$. 


\subsubsection{SEM and EDX analysis of the worn scars of balls}

The SEM and EDX of the worn surfaces of the different balls subjected to wear are shown in Figs. 11-14. The steel ball showed a tinny wear scar when slid against the aged alloy with PAO10 lubrication (Fig. 13). The wear scar became bigger when the ball was subjected to dry friction with the solutionized alloy (Fig. 12). However, the largest scar was on the ball, which was dry slid against the aged alloy (Fig. 11). Moreover, the formation of obvious tribo-layers is highlighted in Figs. 11 and 14, while distinctive furrows appear in Fig. 12. The appearance of $\mathrm{ZrO}_{2}$ (Fig. 14) is similar to that of Fig. 11. The transition of COF, nevertheless, disappears (Fig. 3(a)). The element mapping of the ball surfaces shows that $\mathrm{Ti}$ is transferred to the ball, and the $\mathrm{O}$ signal is indistinct as it is lubricated with
PAO10 (Figs. 13(d)-13(f)). Ti transfers to the ball when it is dry slid against the aged alloy, which can be verified by the EDX. However, the tribo-layers cover merely a part of the surface of the ball in Fig. 12 . Consequently, the COF decrease is directly related to the tribo-layer, and the frictions between the layers are the primary reason for severe to mild transition. It is interesting to note that the wear mechanism and transfer of Ti are relatively similar as the COF displays considerable disparity when the aged alloy is dry sliding against the steel and $\mathrm{ZrO}_{2}$ balls. It suggests that Fe plays a critical role in the transition.

As for the sliding against GCr15 during dry friction, a sequence of complicated processes including plastic deformation of both the surface and subsurface, the formation of wear debris, the transfer of materials,
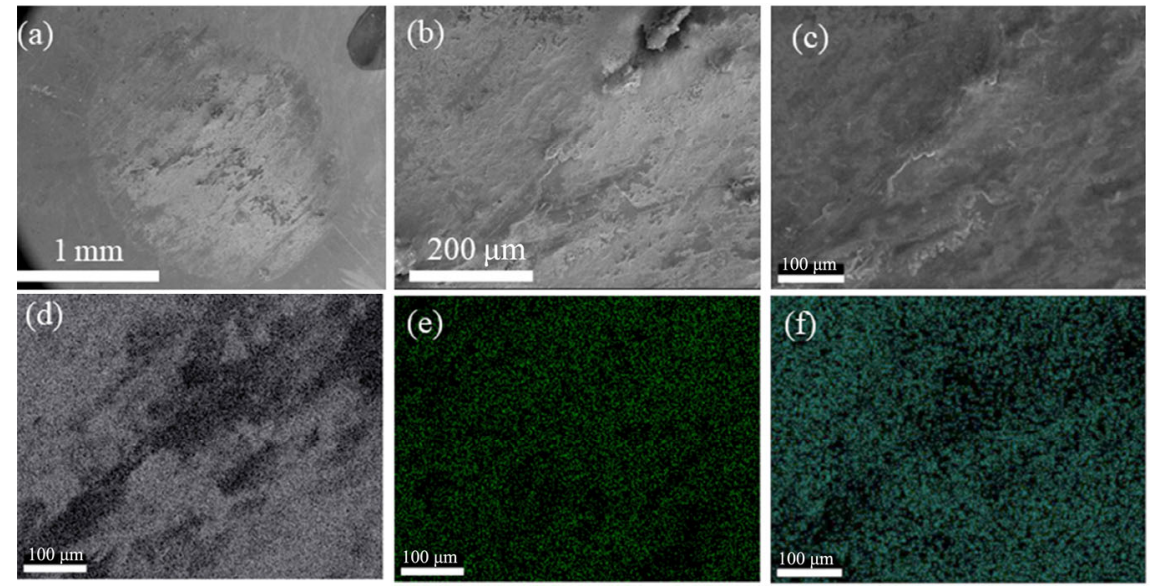

Fig. 11 SEM micrographs of GCr15 subjected to dry sliding against aged TiNi. (a-c) SEM micrographs; chemical mapping of (d) Fe, (e) $\mathrm{O}$, and (f) Ti, respectively.
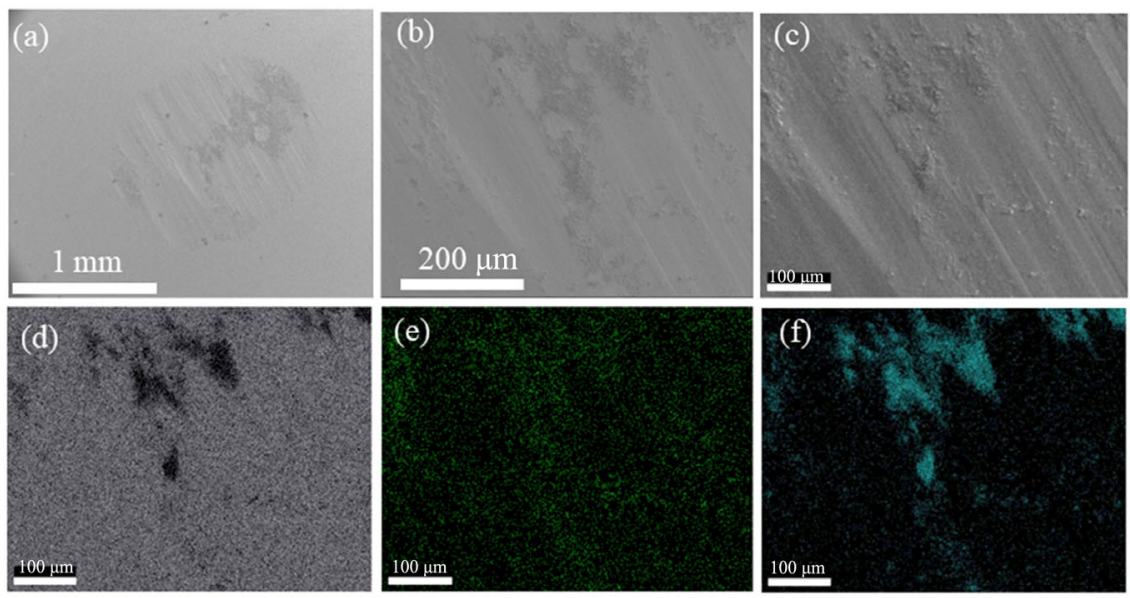

Fig. 12 SEM micrographs of GCr15 subjected to dry sliding against solutionized TiNi. (a-c) SEM micrographs; chemical mapping of (d) $\mathrm{Fe},(\mathrm{e}) \mathrm{O}$, and (f) Ti, respectively. 

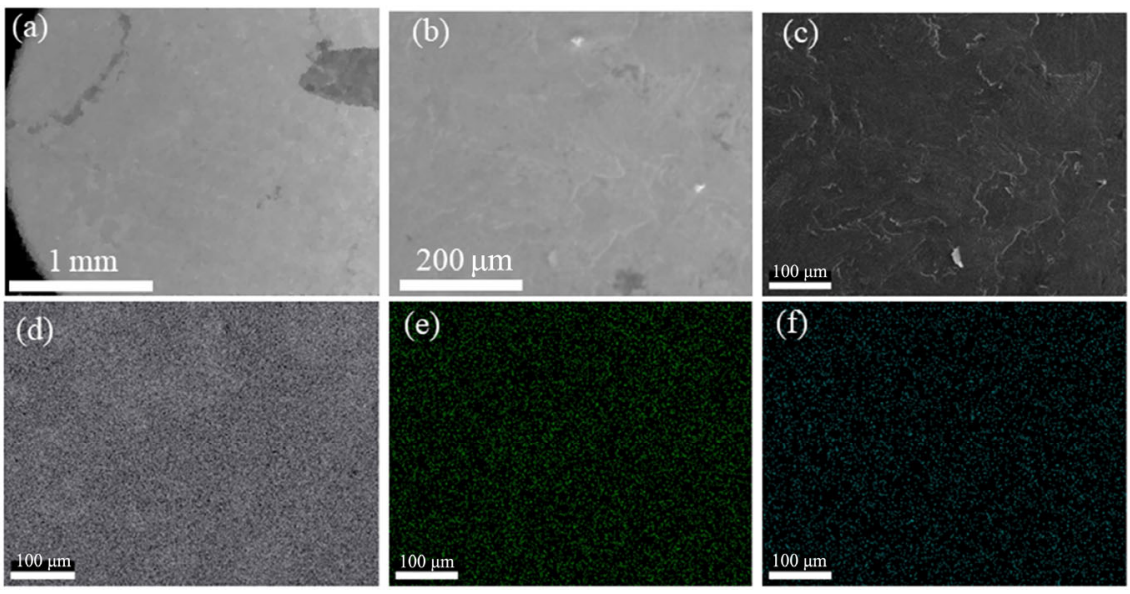

Fig. 13 SEM micrographs of GCr15 subjected to sliding against aged TiNi with PAO10 lubrication. (a-c) SEM micrographs, chemical mapping of (d) Fe, (e) O, and (f) Ti, respectively.
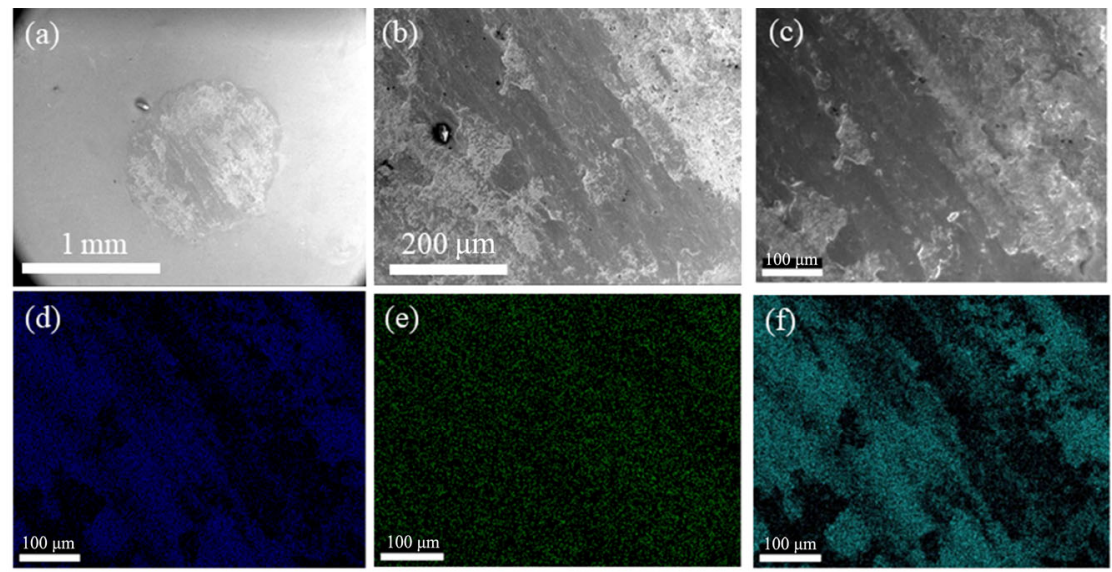

Fig. 14 SEM micrographs of $\mathrm{ZrO}_{2}$ subjected to sliding against aged TiNi. (a-c) SEM micrographs, chemical mapping of (d) Ni, (e) O, and (f) Ti, respectively.

the reaction with the environment, and the mechanical mixing result in the formation of the tribo-layer [31]. The schematic drawing in Fig. 15 presents the formation process of the tribo-layer leading to the remarkable reduction of the COF observed during the sliding of the aged TiNi alloy against GCr15 without lubrication. First, oxygen attaches to the fresh surface of the alloy, and the matrix B2 phase subjected to the stress underneath the contact surface transforms into twinned B19'. As the sliding proceeds, the twinned lamellar B19' is easily changed into an amorphous structure $[1,32]$. In a previous study, the microstructure of the subsurface was shown to be particularly prone to amorphization during dry sliding [33]. The topmost layer of the alloy then becomes brittle, with the formation of inner cracks, and will be delaminated to form wear debris. Moreover, plastic

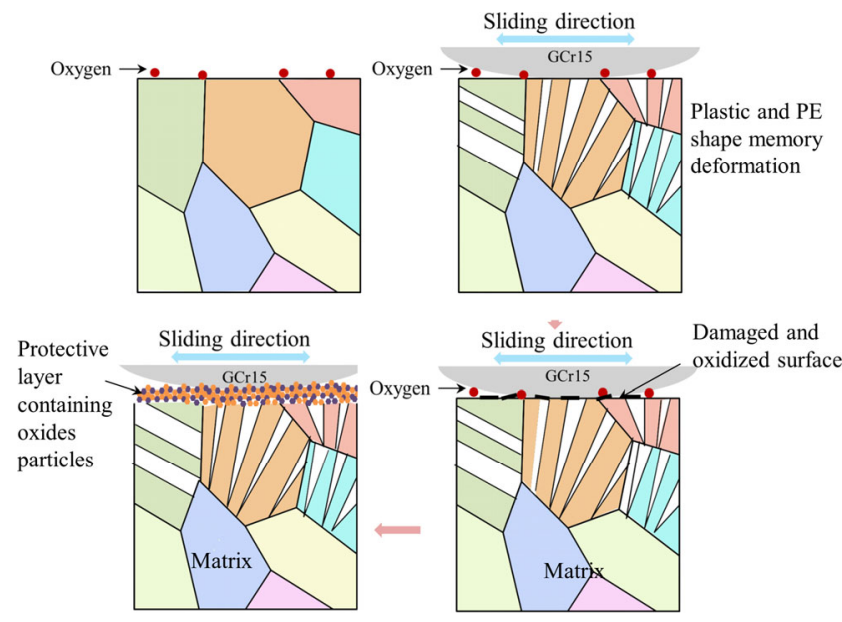

Fig. 15 Diagram of the formation mechanism of the tribo-layer.

deformation of asperities on the surface of the friction pair caused by the contact pressure results in excellent 
adhesion in the process of fretting wears. Low amplitude vibrations shear off the adhesion points and expose the surface of the counterparts. Thus, it reacts with the oxygen in the air to form oxides. The oxidization of the contact surface occurs in the sliding process owing to the friction heat $[18,23]$, especially for the oxidization of Ti. Additionally, the brittle $\mathrm{TiO}_{2}$ layer can be broken easily [34]. The microscale debris will fracture during the process of mechanical mixing, and inner cracks appear. The decrease of the oxygenatom diffusion energy provided by friction with the increase in depth may explain the presence of oxides in the metastable state. The wear debris particles are further refined and oxidized during mechanical mixing in the sliding process.

From the current results, the compact Fe-rich oxides layer on the surface reduces the $\mathrm{COF}$ of aged $\mathrm{Ti}-$ Ni51.5 at\% alloy/GCr15 tribo-pair. However, the COF of the solutionized Ti-Ni51.5 at\% alloy/GCr15 sliding pair does not display abrupt reduction (Fig. 4). The precipitation of the second phase at the nano-scale caused by the aging treatment increases the hardness of the alloy tremendously [24, 25] and accelerates the efficient transfer of Fe to the surface of the TiNi alloy, which is a deciding factor in the formation of $\mathrm{Fe}_{2} \mathrm{O}_{3}$. Steel balls subjected to sliding with the aged alloy generate more wear debris, which exposes smoother surfaces and facilitates the formation of iron oxides. The amount of tribo-oxides, especially the appearance of $\mathrm{Fe}_{2} \mathrm{O}_{3}$, is critical to the protective tribo-layer [16, 23, 35]. Studies have shown that the effect is optimal when the content of $\mathrm{Fe}_{2} \mathrm{O}_{3}$ is $50 \%$ in the case of the titanium/steel tribo-pair [23]. Nevertheless, for the softer alloy in a solutionized state, the transfer of Fe may not be obvious. This is confirmed by the smaller wear scar appearing on the steel ball sliding against the aged alloy (Fig. 11(a)) compared to the one appearing against solutionized one (Fig. 12(a)). Additionally, the frictional heat greatly favors the atomic diffusion and interaction of elements such as $\mathrm{Ti}, \mathrm{O}$, and Fe. The solutionized Ti-Ni51.5 at $\%$ fail to transfer enough Fe from the counterpart to the wear tracks to help form the cover-type tribo-layers of $\mathrm{Fe}_{2} \mathrm{O}_{3}$-rich, which endow a sufficient load-bearing capability to avoid the metal-metal contact [23]. Consequently, the tribo-layer of the solutionized
Ti-Ni51.5 at\% possesses low load-carrying capability, and the local stress concentration delaminates it easily (Figs. 4(e)-4(f)). As a result, the tribo-oxides prevent the metal-metal contact (Figs. 4(a) and 11(a)) for aged alloy but not for solutionized one. However, PAO10 poses an obstacle for the continuous supply of oxygen to the contact surface, thereby leading to heavy wear. Meanwhile, tribo-oxides without the $\mathrm{Fe}_{2} \mathrm{O}_{3}$ particles induced when the ceramics counterparts $\left(\mathrm{Al}_{2} \mathrm{O}_{3}\right.$ and $\mathrm{ZrO}_{2}$ ) slid against the Ti-Ni51.5 at $\%$ alloy show no sign of protection, although oxides are introduced in the process. Nevertheless, the layers tend to be largely destroyed and cannot serve as properly protective tribo-layers.

\section{Conclusions}

1) The aged Ti-Ni51.5 at\%/GCr15 couple under dry sliding shows clear signs of a severe-mild transition under a load of $20 \mathrm{~N}$, stroke of $1 \mathrm{~mm}$, and frequency of $20 \mathrm{~Hz}$, but this transition disappears when it is lubricated with PAO10 or when the counterpart is replaced by an $\mathrm{Al}_{2} \mathrm{O}_{3}$ or $\mathrm{ZrO}_{2}$ counterpart.

2) The severe-mild transition is absent from the friction process for the solutionized Ti-Ni51.5 at\%/ GCr15 couple when the microhardness decreases from 3,650 MPa in the aged state to 2,807 MPa in the solutionized state. The wear scar on the steel ball when it is slid against the aged alloy is more severe than on the one slid against the solutionized alloy. Thus, it confirms that the transfer of $\mathrm{Fe}$ is more apparent in the former friction pair. The improvement of superelasticity and microhardness by aging treatment are critical for the transition.

3) The formation of the protective tribo-layer, caused by the transfer of Fe from GCr15 onto the shape memory alloy and the mixture of oxides generated by friction heat, is the main reason for the severe-mild transition. The layer is complicated and consists of particles such as $\mathrm{TiO}_{2}, \mathrm{Fe}_{2} \mathrm{O}_{3}$, and an amorphous phase.

\section{Acknowledgements}

This work was supported by the National Natural Science Foundation of China (51673205), the Key 
Research Program of Frontier Science, Chinese Academy of Sciences (QYZDJ-SSW-SLH056), and the National Basic Research Program of China (2015CB057502).

Open Access This article is licensed under a Creative Commons Attribution 4.0 International Li-cense, which permits use, sharing, adaptation, distribution and reproduction in any medium or for-mat, as long as you give appropriate credit to the original author(s) and the source, provide a link to the Creative Commons licence, and indicate if changes were made.

The images or other third party material in this article are included in the article's Creative Commons licence, unless indicated otherwise in a credit line to the material. If material is not in-cluded in the article's Creative Commons licence and your intended use is not permitted by statutory regulation or exceeds the permitted use, you will need to obtain permission directly from the copyright holder.

To view a copy of this licence, visit http://creativecommons.org/licenses/by/4.0/.

\section{References}

[1] Otsuka K, Ren X. Physical metallurgy of Ti-Ni-based shape memory alloys. Prog Mater Sci 50(5): 511-678 (2005)

[2] Misochenko A A, Chertovskikh S V, Shuster L S, Stolyarov $\mathrm{V}$ V. Influence of grain size and contact temperature on the tribological behaviour of shape memory Ti49.3Ni50.7 alloy. Tribol Lett 65(4): 7 (2017)

[3] Khanlari K, Ramezani M, Kelly P, Cao P, Neitzert T. Comparison of the reciprocating sliding wear of $58 \mathrm{Ni39Ti-}$ 3Hf alloy and baseline 60NiTi. Wear 408-409: 120-130 (2018)

[4] Tang G H, Ho J K L, Dong G N, Hua M. Fabrication self-recovery bulge textures on TiNi shape memory alloy and its tribological properties in lubricated sliding. Tribol Int 96: 11-22 (2016)

[5] Cameron N, Farhat Z. Fabrication, characterization, and evaluation of monolithic NiTi nanolaminate coatings. Tribol T 62(6): 1007-1018 (2019)

[6] Abedini M, Ghasemi H M, Ahmadabadi M N. Tribological behavior of NiTi alloy in martensitic and austenitic states. Mater Design 30(10): 4493-4497 (2009)

[7] Yan L N, Liu Y. Effect of temperature on the wear behavior of NiTi shape memory alloy. J Mater Res 30(2): 186-196 (2015)
[8] Levintant-Zayonts N, Starzynski G, Kucharski S, Kopec M. Characterization of NiTi SMA in its unusual behaviour in wear tests. Tribol Int 137: 313-323 (2019)

[9] Tang G H, Zhang D Y, Zhang J F, Lin P, Dong G N. Selfrecovery of worn surface of TiNi shape memory alloy. Appl Surf Sci 321: 371-377 (2014)

[10] Wang Y X, Xu R B, Hu S M, Tu F Q, Jin W W. Research combining experiment and FEM analysis on sliding wear behaviors and mechanisms of TiNi alloy. Wear 386-387: 218-222 (2017)

[11] Feng X Q, Qian L M, Yan W Y, Sun W Y. Wearless scratch on NiTi shape memory alloy due to phase transformational shakedown. Appl Phys Lett 92(12): 3 (2008)

[12] Ren F, Arshad S N, Bellon P, Averback R S, Pouryazdan M, Hahn H. Sliding wear-induced chemical nanolayering in $\mathrm{Cu}-\mathrm{Ag}$, and its implications for high wear resistance. Acta Mater 72: 148-158 (2014)

[13] Liu Z, Patzig C, Selle S, Hoeche T, Gumbsch P, Greiner C. Stages in the tribologically-induced oxidation of high-purity copper. Scripta Mater 153: 114-117 (2018)

[14] Philipp G G, Sebastian R, Dominic R, Christian M, Frank $\mathrm{M}$, Sebastian S. Interplay between microstructural evolution and tribo-chemistry during dry sliding of metals. Friction 7(6): 637-650 (2019)

[15] Chen X, Schneider R, Gumbsch P, Greiner C. Microstructure evolution and deformation mechanisms during high rate and cryogenic sliding of copper. Acta Mater 161: 38-149 (2018)

[16] Zhang Q, Guo X, Zhang M, Ding H, Zhou G. Severeto-mild weart ransition of $\mathrm{Ti}-6.5 \mathrm{Al}-3.5 \mathrm{Mo}-1.5 \mathrm{Zr}-0.3 \mathrm{Si}$ alloy accelerated by Fe-rich oxide tribolayers. Tribol Lett 67(1): 17 (2019)

[17] Wang S S, Jiang J T, Fan G H, Panindre A M, Frankel G S, Zhen L. Accelerated precipitation and growth of phases in an $\mathrm{Al}-\mathrm{Zn}-\mathrm{Mg}-\mathrm{Cu}$ alloy processed by surface abrasion. Acta Mater 131: 233-245 (2017)

[18] Zhou Y, Wang S Q, Huang K Z, Zhang B, Wen G H, Cui $\mathrm{X}$ H. Improvement of tribological performance of TC11 alloy via formation of a double-layer tribolayer containing graphene/ $\mathrm{Fe}_{2} \mathrm{O}_{3}$ nanocomposite. Tribol Int 109: 485-495 (2017)

[19] Yin C H, Liang Y L, Liang Y, Li W, Yang M. Formation of a self-lubricating layer by oxidation and solid-state amorphization of nano-lamellar microstructures during dry sliding wear tests. Acta Mater 166: 208-220 (2019)

[20] Chen X, Han Z, Li X, Lu K. Lowering coefficient of friction in $\mathrm{Cu}$ alloys with stable gradient nanostructures. Sci $A d v$ 2(12): e1601942 (2016) 
[21] Curry J F, Babuska T F, Furnish T A, Lu P, Adams D P, Kustas A B, Nation B L, Dugger M T, Chandross M, Clark B G, Boyce B L, Schuh C A, Argibay N. Achieving ultralow wear with stable nanocrystalline metals. Adv mater 32(30): 1802026 (2018)

[22] Rasool G, Stack M M. Tribo-oxidation maps for Ti against steel. Tribol Int 91: 258-266 (2015)

[23] Zhang Q Y, Zhou Y, Li X X, Wang L, Cui X H, Wang S Q. Accelerated formation of tribo-oxide layer and its effect on sliding wear of a titanium alloy. Tribol Lett 63(1): 1-13 (2016)

[24] Fan Q C, Zhang Y H, Wang Y Y, Sun M Y, Meng Y T, Huang $\mathrm{S}$ K, Wen Y H. Influences of transformation behavior and precipitates on the deformation behavior of Ni-rich NiTi alloys. Mater Sci Eng A 700: 269-280 (2017)

[25] Kim J I, Miyazaki S. Effect of nano-scaled precipitates on shape memory behavior of Ti-50.9at.\%Ni alloy. Acta Mater 53(17): 4545-4554 (2005)

[26] Kato H., Komai K.: Tribofilm formation and mild wear by tribo-sintering of nanometer-sized oxide particles on rubbing steel surfaces. Wear 262(1-2): 36-41(2007)

[27] Mathur S, Vyas R, Sachdev K, Sharma S K. XPS characterization of corrosion films formed on the crystalline, amorphous and nanocrystalline states of the alloy Ti60Ni40. J Non-Crystal Solids 357(7): 1632-1635 (2011)

[28] Ma L, Wiame F, Maurice V, Marcus P.: New insight on early oxidation stages of austenitic stainless steel from in situ XPS analysis on single-crystalline $\mathrm{Fe}-18 \mathrm{Cr}-13 \mathrm{Ni}$. Corrosion

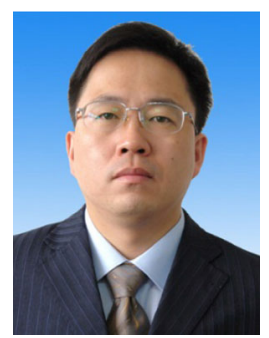

Qihua WANG. He graduated from the Northwestern Polytechnical University with a bachelor's degree in engineering in 1990 and a Ph.D. in Lanzhou Institute of Chemical Physics, Chinese Academy of Sciences in 1998. In 2004, he worked as a senior visiting scholar at the Department of Chemistry at the University of Houston, USA. He

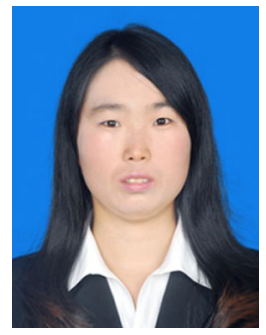

Rui YANG. She is a Ph.D. candidate in Lanzhou Institute of Chemical Physics, Chinese Academy of Sciences, University of Chinese
Science 140, 205-216 (2018)

[29] Kubala-Kukus A, Banas D, Stabrawa I, Szary K, Sobota D, Majewska U, Wudarczyk-Mocko J, Braziewicz J, Pajek M. Analysis of $\mathrm{Ti}$ and $\mathrm{TiO}_{2}$ nanolayers by total reflection X-ray photoelectron spectroscopy. Spectrochim Acta B 145: 43-50 (2018)

[30] Menapace C, Leonardi M, Matejka V, Gialanella S, Straffelini G. Dry sliding behavior and friction layer formation in copper-free barite containing friction materials. Wear 398: 191-200 (2018)

[31] Stott F H. High-temperature sliding wear of metals. Tribol Int 35(8): 489-495 (2002)

[32] $\mathrm{Hu} \mathrm{T}$, Chu C L, Wu S L, Xu R Z, Sun G Y, Hung T F, Yeung K W K, Wu Z W, Li G Y, Chu P K. Microstructural evolution in NiTi alloy subjected to surface mechanical attrition treatment and mechanism. Intermetallics 19: 11361145 (2011)

[33] Yang R, Ma W, Duan C J, Yang Z H, Zhang X R, Wang T M, Wang Q H. Microstructure responses and deformation mechanisms of solutionized Ti-51.5 at.\%Ni Alloy during reciprocating sliding. Tribol Int 140: 105816 (2019)

[34] Mahmud A, Wu Z G, Zhang J S, Liu Y N, Yang H. Surface oxidation of NiTi and its effects on thermal and mechanical properties. Intermetallics 103: 52-62 (2018)

[35] Chen K M, Zhou Y, Li X X, Zhang Q Y, Wang L, Wang $\mathrm{S}$ Q. Investigation on wear characteristics of a titanium alloy/steel tribo-pair. Mater Design 65: 65-73 (2015)

is currently a researcher and doctoral supervisor. He is the winner of the National Outstanding Youth Fund and his current research interests include composite tribology, space environmental material failure behavior and mechanism, and lubrication materials and sealing techniques under severe conditions. He has published more than 100 papers in important journals at domestic and international. As a group leader, he has undertaken more than 20 research projects.

Academy of Sciences. Her research focuses on the tribological problems of shape memory alloys and the development of metal-based wear-resistant materials. 